\title{
Methylphenidate enhances neuronal differentiation and reduces proliferation concomitant to activation of Wnt signal transduction pathways
}

\author{
Edna Grünblatt $\mathbb{D}^{1,2,3}$, Jasmin Bartl ${ }^{1,4}$ and Susanne Walitza (iD ${ }^{1,2,3}$
}

\begin{abstract}
Methylphenidate (Ritalin) is the most commonly prescribed drug in the treatment of attention-deficit hyperactivity disorder. It is suggested that in vivo, methylphenidate treatment supports cortical maturation, however, the molecular and cellular mechanisms are not well understood. This study aimed to explore the potential effect of methylphenidate on cell proliferation and maturation in various cellular models, hypothesizing its interaction with the Wnt-signaling. The termination of cell proliferation concomitant to neuronal maturation following methylphenidate treatment was observed in all of the cell-models tested: murine neural stem-, rat PC12- and the human SH-SY5Y-cells. Inhibition of Wnt-signaling in SH-SY5Y cells with Dkk1 30 min before methylphenidate treatment suppressed neuronal

differentiation but enhanced proliferation. The possible involvement of the dopamine-transporter in cell differentiation was discounted following the observation of opposing results after GBR-12909 treatment. Moreover, Wnt-activation via methylphenidate was confirmed in Wnt-luciferase-reporter assay. These findings reveal a new mechanism of action of methylphenidate that might explain long-term effects.
\end{abstract}

\section{Introduction}

The neurodevelopmental disorder attention-deficit hyperactivity disorder (ADHD) is one of the most common psychiatric and behavioral disorders in children and adolescents, often persisting into adulthood ${ }^{1}$. Delayed cerebral cortex maturation (thickness and surface area), in particular in frontal regions known to be important in the control of cognitive processes concomitant to alterations in basal ganglia formations, were reported in children and adolescents with $\mathrm{ADHD}^{2,3}$. These have also been linked to adult $\mathrm{ADHD}^{4}$. Moreover, ventral and dorsal striatal surface reduction, associated with reward processing, executive

\footnotetext{
Correspondence: Edna Grünblatt (edna.gruenblatt@kjpd.uzh.ch)

${ }^{1}$ Department of Child and Adolescent Psychiatry and Psychotherapy, University Hospital of Psychiatry Zurich, University of Zurich, Zürich, Switzerland

${ }^{2}$ Neuroscience Center Zurich, University of Zurich and the ETH Zurich, Zürich, Switzerland

Full list of author information is available at the end of the article

These authors contributed equally: Edna Grünblatt and Jasmin Bartl.
}

function and motor planning, respectively ${ }^{5,6}$ have also been observed in ADHD. Psychostimulants, in particular methylphenidate $(\mathrm{MPH})$ and amphetamine, provide an effective treatment for $\mathrm{ADHD}^{7}$, although their effects on brain development, maturation and its safety have been discussed controversially ${ }^{8-11}$. Nevertheless, several studies point to the beneficial effects of psychostimulant treatment on brain function and structure in $\mathrm{ADHD}^{6,9-11}$. So far it is known that MPH binds with high affinity to the dopamine transporter, and with lower affinity to the norepinephrine transporter and serotonin transporter, and inhibits the transport of synaptic monoamines back into the neuron ${ }^{12}$. However, given the extent of MPH prescription ${ }^{13}$, and the levels of misuse amongst youth and young adults ${ }^{14}$, particularly at sensitive developmental stages in regard to brain maturation, concerns over adverse effects (e.g., neurogenesis, neuronal development, maturation, receptor densities or connectivity) have been raised. Few studies have looked 
into neurodevelopmental effects of MPH treatment, in vitro and in vivo. In vivo, several studies have observed that $\mathrm{MPH}$ treatment was associated with neurogenesis and cell differentiation in rodents ${ }^{15,16}$. Recently, 2 and $5 \mathrm{mg} / \mathrm{kg}$ (oral) $\mathrm{MPH}$ treatment in adolescent rats over a five-week period reportedly increased hippocampal neurogenesis and inward shape deformations. This was not observed in adult rats with the same treatment ${ }^{17}$. An in vitro study of neuronal maturation following $\mathrm{MPH}$ treatment $(1-100 \mathrm{nM}$, doses correlating to oral intake of $1 \mathrm{mg} / \mathrm{kg} \mathrm{MPH}$ in patients' serum $^{18,19}$ ) in murine neural stem cells (mNSC) found that MPH enhanced cell differentiation, but inhibited cell proliferation ${ }^{20}$. However, the cellular and molecular mechanism affected by MPH treatment is not yet fully understood.
Therefore, the current study aims to extend our previous mNSC pilot study ${ }^{20}$ by using three cell culture models: mNSC, rat pheochromocytoma-12 (PC12) and the human neuroblastoma SH-SY5Y cells. Moreover, following the observed differentiation effect of $\mathrm{MPH}$ on the cells, we hypothesized the possible involvement of the canonical Wnt-signaling pathway ${ }^{21-23}$. Our hypothesis is based on the fact that Wnt-signaling plays a role in several cellular and physiological processes, regulating cell proliferation, differentiation, migration, and patterning during embryonic development, and tissue homeostasis in adults, but is specifically needed in the maturation and differentiation of $\mathrm{NSC}^{24}$. Two approaches will be used to test this hypothesis. First, a pharmacological approach in
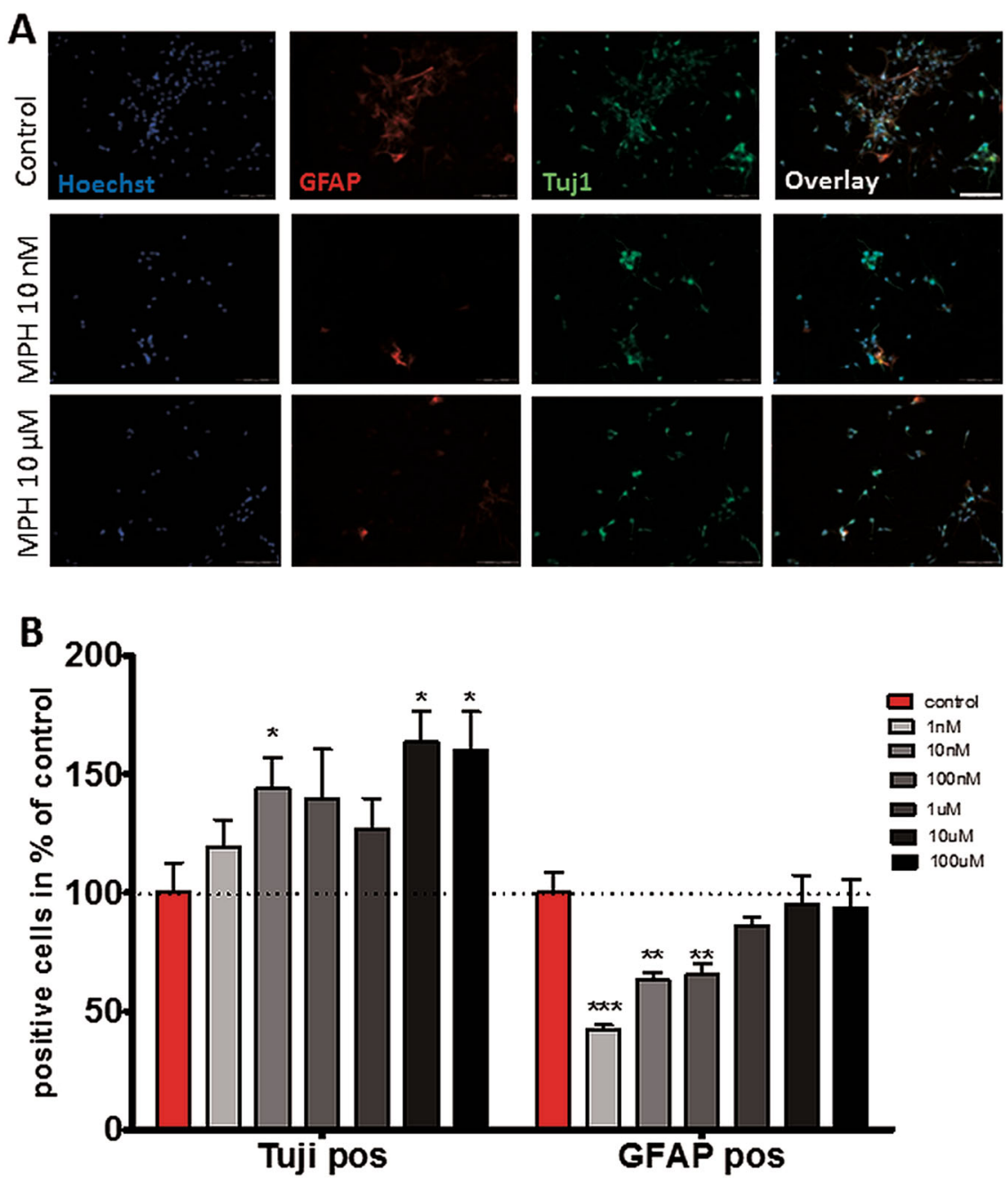

Fig. 1 Effect of MPH on embryonic mNSC differentiation into astrocyte (GFAP ${ }^{+}$cells) and neurons (Tuj ${ }^{+}$cells). a Representative immunocytochemistry staining (control, MPH $10 \mathrm{nM}$ and $10 \mu \mathrm{M}$; see Supplementary Fig. S1 for all MPH doses) of embryonic mNSC against GFAP (red), Tuj 1 (green) and for total cell count using Hoechst 33258 staining (blue). Scale bar $=50 \mu \mathrm{m}$. b MPH treatment induced differentiation of mNSC into Tuj1 positive neurons showing significance starting with $10 \mathrm{nM} \mathrm{MPH}$ treatment, while suppressing differentiation into GFAP-positive astrocytes. Results presented as percent of control treatment showing mean value, and the s.e.m. Kruskal-Wallis followed by Mann-Whitney Test ${ }^{*} p<0.05$ vs. control, ${ }^{* *} p<0.01$ vs. control, ${ }^{* * *} p<0.001$ vs. control; $n=5$ repeats 
which we will compare the effects of treating the human SH-SY5Y cells with MPH to those treated with either Rspondin 1 (Wnt activator), GBR-12909 (selective dopamine transporter inhibitor), or by blocking the Wntsignaling with Dickkopf-1 (Dkk1; antagonistic inhibitor of the Wnt-signaling, binds to low-density lipoprotein receptor-related protein 5/6; LRP5/6) 30 min before MPH treatment. In the second approach, we will use a cellbased luciferase assay in mouse fibroblast cells engineered with the firefly luciferase reported gene under the control of Wnt-responsive promoters (TCF/LEF), enabling us to measure $W n t / \beta$-catenin-activity after pharmacological treatment with $\mathrm{MPH}$.

\section{Material and methods}

\section{Preparation of compound solution}

Specification of compound solution preparation is described under Supplementary Material And Methods in details.

\section{Murine neuronal stem cell (mNSC) sphere monolayer culturing and differentiation study}

mNSCs were derived from the hippocampus tissue of albino mouse (Charles River, Switzerland) embryos on embryonic day 15 (E15). All animal procedures were performed in accordance with National Institute of Health, and the Cantonal Veterinary office Zurich for the care and use of laboratory animals' guidelines (Ethic permission 223/2014). Cells were cultured in a defined medium (NeuroCult Proliferation Kit (Mouse); Stemcell, Germany) for 6 days at $37^{\circ} \mathrm{C}$ and $5 \% \mathrm{CO}_{2}$. After 6 days, the grown NSC spheres were harvested and prepared for differentiation. mNSC spheres were collected and plated on a $30 \mu \mathrm{g} / \mathrm{ml}$ poly-L-lysine (Sigma aldrich, Switzerland) and $20 \mu \mathrm{g} / \mathrm{ml}$ laminine (Invitrogen, Switzerland) coated 8well glass cover-slip and incubated for another four days creating a monolayer (see example Fig. 1a). Each well had a final concentration of $22.8 \times 10^{4}$ cells $/ \mathrm{ml}$ cultured in NeuroCult Differentiation Kit (Mouse) (Stemcell, Germany). The cells were treated directly after seeding to the cover-slip using different concentration $(1 \mathrm{nM}$, up to 100 $\mu \mathrm{M})$ of MPH or water as control. On the last day, cells were fixed with $4 \%$ paraformaldehyde for $20 \mathrm{~min}$ at room temperature and stained for glial fibrillary acidic protein (GFAP; 1:200, Sigma aldrich, USA, Cat-No: C4546), $\beta$ tubulin III (Tuj 1; 1:300, Sigma aldrich, USA, Cat-No: T3952), and Hoechst 33258 staining (1:100; Invitrogen, Cat-No: H3569) (for detailed Immunocytochemistry procedure see supplementary material and methods).

\section{Statistical analysis}

The staining's were analyzed for the cell count of astrocytes (GFAP-positive cells) and immature neurons (Tuj 1 positive cells) in comparison to the total number of cells (Hoechst positive cells) using the Kruskal-Wallis followed by Mann-Whitney Test. In order to present results in comparison to the untreated cells, percentages were calculated for each treatment dose, setting the control as $100 \%$. Analysis was conducted using SPSS version 22 software program (IBM, USA). A $p$-value < 0.05 was set as significant. There were at least five independent experiments, and five pictures per well (treatment) were analyzed.

\section{Neuronal cell line culture}

For the standard culturing and differentiation procedure of human neuroblastoma SH-SY5Y cells (European Collection of Authenticated Cell Cultures (ECACC), UK) and rat pheochromocytoma (PC12) cells (ECACC, UK) see supplementary material and methods.

\section{Treatment of SH-SY5Y and PC12 cells}

In the proliferating experiment, $\mathrm{PC} 12$ cells were treated once with either MPH or water (Fig. 2a). In the differentiation experiment, PC12 cells were treated every $24 \mathrm{~h}$ with either MPH or water and the morphological classification of cell differentiation was done after 6 days of culturing in differentiation medium (DM), consisting of a normal growth medium supplemented with $10 \mu \mathrm{M}$ retinoic acid (Sigma Aldrich, Switzerland) and $50 \mathrm{ng} / \mathrm{ml}$ nerve growth factor (Sigma Aldrich, Switzerland; Fig. 2d).

In the proliferating experiments, SH-SY5Y cells were treated once with either MPH, GBR12909 (cat. no. D052; Sigma Aldrich, Switzerland), R-spondin 1 (cat. no. SRP6487; Sigma Aldrich, Switzerland), compared to vehicle water or DMSO. For Wnt-signaling pathway inhibition, Dkk-1 (cat. no. SRP3258; Sigma Aldrich, Switzerland) was added $30 \mathrm{~min}$ before cells were treated with MPH (Fig. 3a, b). In the differentiation experiment, SH-SY5Y cells were treated every $24 \mathrm{~h}$ with different doses of either MPH, GBR12909, R-spondin 1, compared to vehicle water or DMSO. While in the Wnt-signaling pathway inhibition, Dkk-1 was added 30 min before cells were treated with MPH. The morphological classification of cell differentiation was conducted after 3 days of culturing in DM (Fig. 4a, b).

\section{$x$ CELLigence analysis for cell proliferation or cytotoxicity}

Cell viability and proliferation after acute treatment with MPH was monitored using the real-time xCELLigence analyzer from Roche. 96-well E-plates (ACEA, USA) were coated using $40 \mu \mathrm{l} /$ well collagen-I solution (ScienCell, USA) for both cell types. The background cell impedance of the pure growth medium without cells was measured, before SH-SY5Y cells were seeded at a concentration of $5 \times 10^{4}$ cells/well and PC12 at $1 \times 10^{4}$ cells/ well. The baseline cell index $(\mathrm{CI})$ was measured every $15 \mathrm{~min}$ for $24 \mathrm{~h}$. Afterwards the cells were treated with 


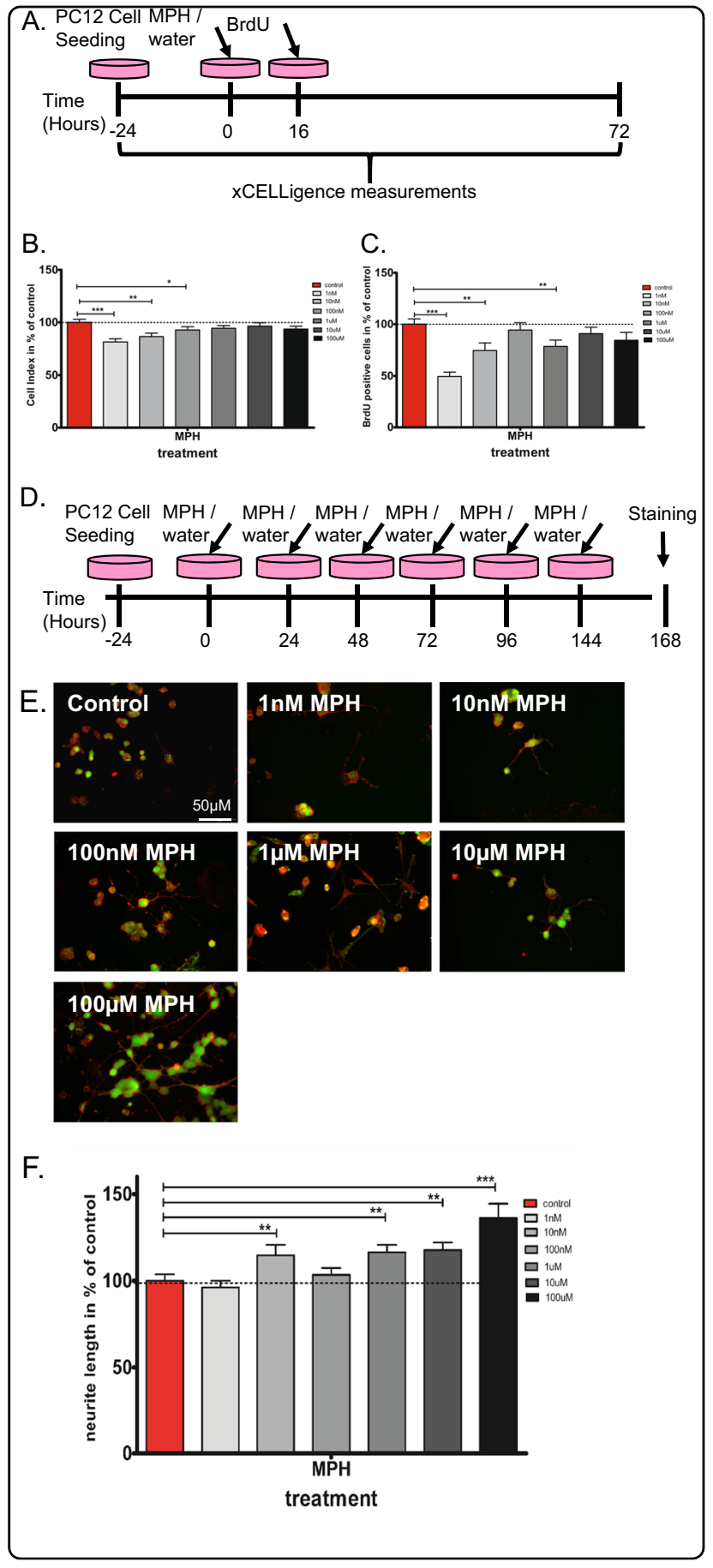

different doses of $\mathrm{MPH}$, whereas CI was measured continuously every minute for two hours and every $15 \mathrm{~min}$ for another $48 \mathrm{~h}$.

Statistical analysis of $\mathbf{x C E L L i g e n e c e ~ r e s u l t s ~ R a w ~ d a t a ~}$ from the $\mathrm{xCELLigence} \mathrm{system} \mathrm{presented} \mathrm{as} \mathrm{CI}$ values were used for the statistical analysis with the statistical software program StatView 5.0 (SAS Institute Inc.Cary, NC, USA).
Fig. 2 Influence of MPH treatment on PC12 cells proliferation and differentiation. Proliferation: (a) the time line of cell culturing, treatment and proliferation measurements. b Mean cell index (impedance measured by $\times$ CELLigence) values as $\%$ of control \pm s.e.m. at $16 \mathrm{~h}$ after $\mathrm{MPH}$ treatment $(1 \mathrm{nM}-100 \mu \mathrm{M})$ showing significant decrease in cell proliferation. c Mean of BrdU positive cells as \% of control \pm s.e.m. at $16 \mathrm{~h}$ after MPH treatment $(1 \mathrm{nM}-100 \mu \mathrm{M})$ resulted in a significant decrease in cell proliferation. Mann-Whitney ${ }^{*} p<0.05$;

${ }^{* *} p<0.01 ;{ }^{* *} p<0.005$. Differentiation: (d) the time line of cell

culturing, treatment and neurite outgrowth determination via 'Neurite outgrowth staining kit' (Thermo Fisher) for differentiation evaluation. e Representative neurite outgrowth staining of vehicle and $\mathrm{MPH}$ $(1 \mathrm{nM}-100 \mu \mathrm{M})$ treated PC12 cells. Scale bar $=50 \mu \mathrm{M}$. f Neurite outgrowth was significantly increased after $10 \mathrm{nM}$ up to $100 \mu \mathrm{M} \mathrm{MPH}$ treatment. Mann-Whitney test ${ }^{* *} p<0.05$ and ${ }^{* * *} p<0.01$ vs. control. $n$ $=4-5$ independent experiments with 4-6 internal replications

Determination of the first significant time point in which MPH alters cell proliferation in comparison with untreated cells was conducted using self-written MATLAB programs in which all impedance measures with time and dose were evaluated (Supplementary Fig. S2 $\mathrm{B}$ and $\mathrm{C})$. For this, the CI data were exported from the xCELLigence software into an excel file followed by coma separated value file. For each time point measurement, outliers were detected and removed (CI values more than two s.d., but only if it was more than one s.d. away from the plate mean at this time point). Comparison was carried out for each measured time point by calculating mean, s.d. and number of wells used to calculate the two values for the two replicate groups. The Welch's $t$-test was applied. The $p$-value was plotted semi logarithmic and with inverted axis against the time scale, thus the more significant a p-value, the higher the peak on the plot. $p$ value $<0.01$ were set as significant (Supplementary Fig. $\mathrm{S} 2 \mathrm{C}$ ). The demonstrated values were calculated in percent relative to control levels (100\%; control was water).

\section{BrdU Incorporation}

The SH-SY5Y cells were seeded into poly-D-lysine/ laminin coated eight-well slides at a density of $3 \times 10^{4}$ cells/ well and the PC12 cells were seeded at the same density into Collagen I coated eight-well slides. The cells were incubated at $37{ }^{\circ} \mathrm{C}$ in a humidified atmosphere of $5 \% \mathrm{CO}_{2}$ for $24 \mathrm{~h}$. SH-SY5Y cells were treated with different doses of MPH $(1 \mathrm{nM}-100 \mu \mathrm{M})$, GBR12909 $(1 \mathrm{nM}-10 \mu \mathrm{M})$, RSpondin1 (100 ng/ml), dkk1 (200 ng/ml) alone, or $30 \mathrm{~min}$ before MPH was added, (vehicle was water or DMSO) and incubated for $16 \mathrm{~h}$. This time point of assessment was determined according to the xCELLigence results (see section 'xCELLigence analysis for cell proliferation or cytotoxicity'). PC12 cells were treated with either MPH or water followed by incubation for $16 \mathrm{~h}$. After incubation $10 \mu \mathrm{M}$ of the thymidine-analog 5-bromodeoxyuridine 


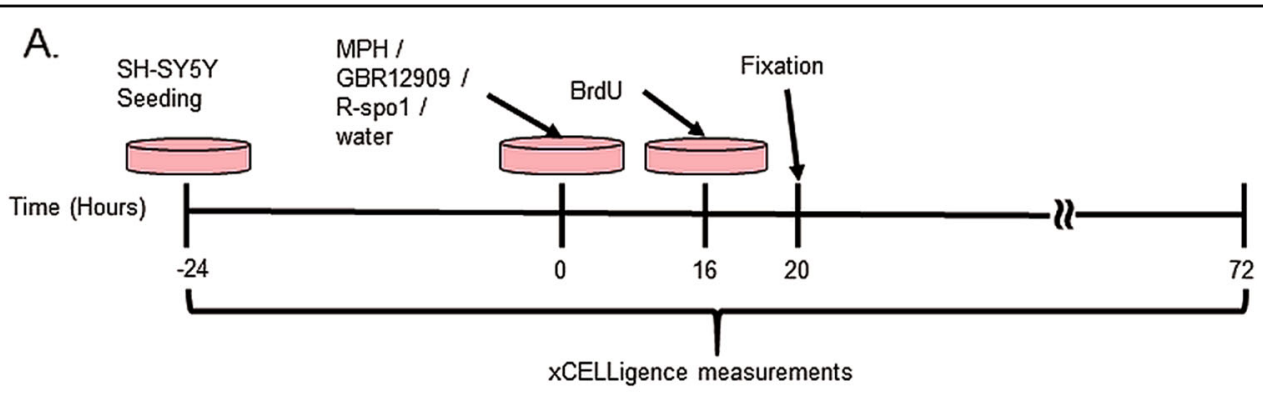

B.

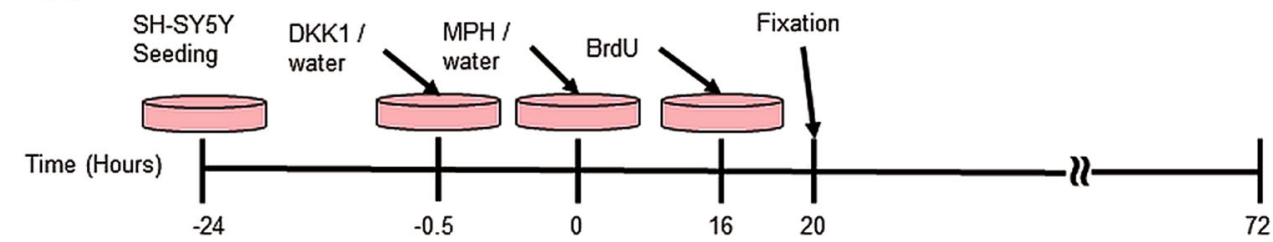

C.

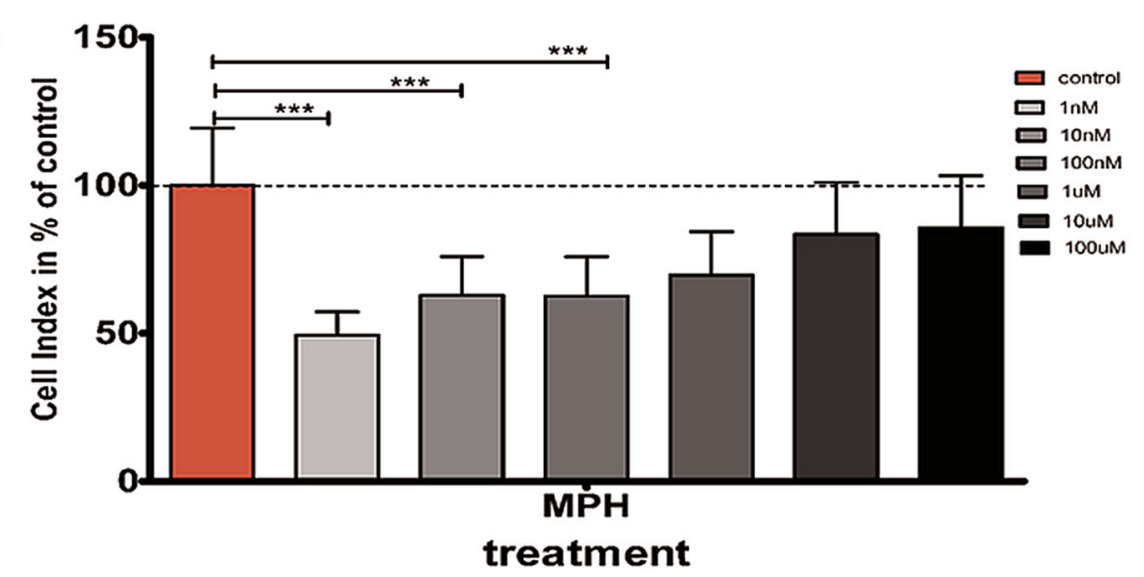

D.

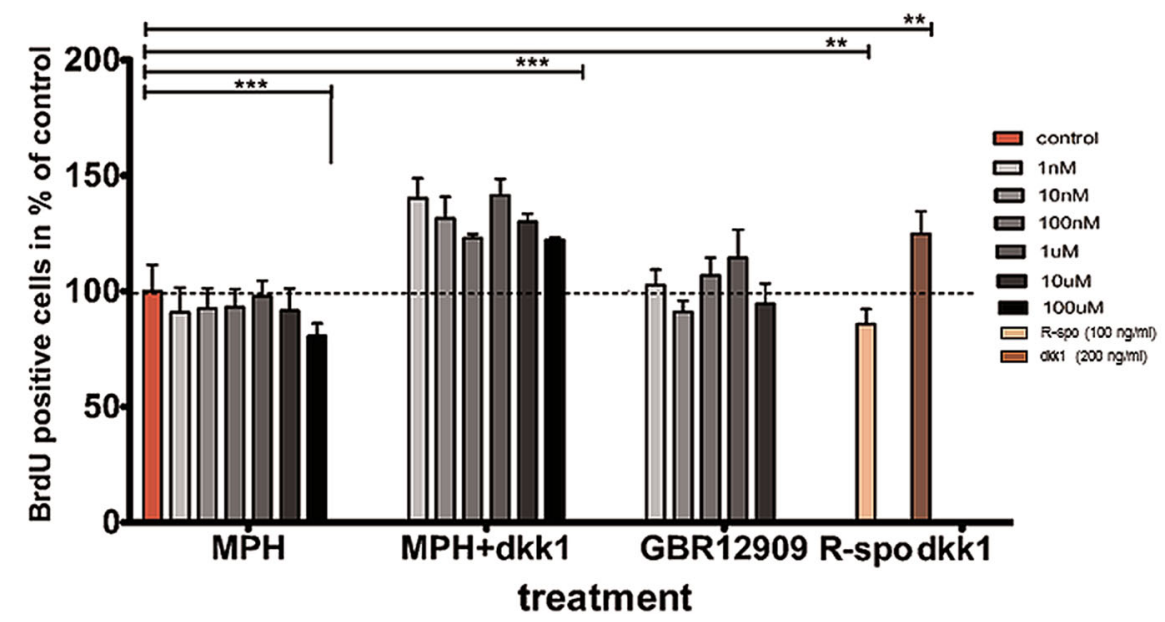

Fig. 3 (See legend on next page.) 


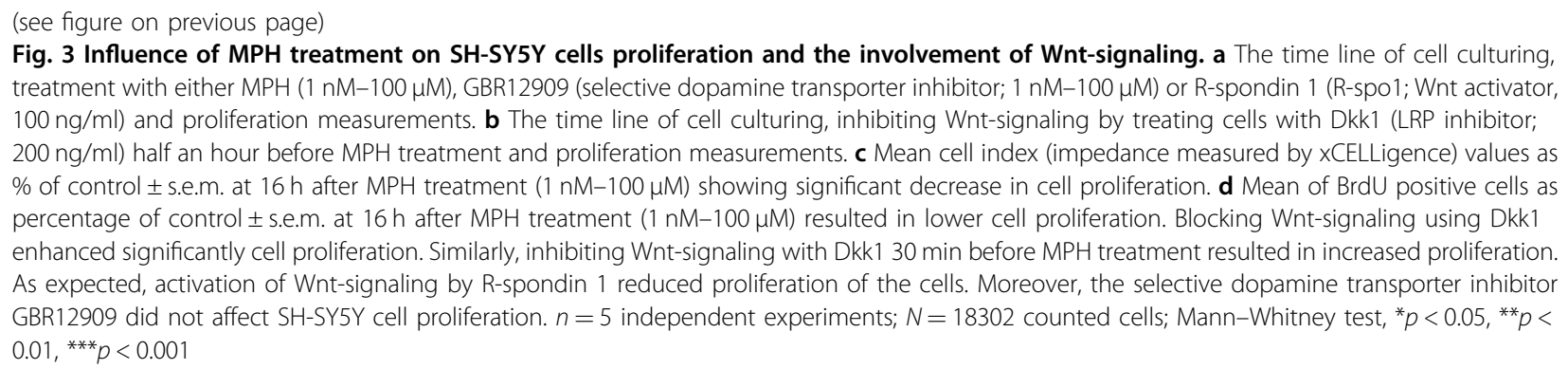

(BrdU) was added to the cells and incubated for $4 \mathrm{~h}$ at $37^{\circ}$ C. Cells were fixed with $4 \%$ ice-cold paraformaldehyde (SantaCruz Biotechnologies, Switzerland) followed by standard procedure of staining (see Supplementary Material And Methods). Pictures were taken at $\times 20$ magnification under the inverted microscope (Olympus IX81, Germany) with DP72 Digital camera. Cells were counted using the xcellence software (Olympus, Germany).

\section{Cytotoxicity and apoptosis}

ApoTox-Glo Triplex Assay and CellTox Green Cytotoxicity Assay from Promega (Switzerland) were used to determine the possible toxic effect of MPH on PC12 cells. For testing the cytotoxicity and apoptosis effect, PC12 cells were seeded at $10^{4}$ cells/well onto Collagen I treated black 96-well plates and were cultivated for $24 \mathrm{~h}$ at $37^{\circ} \mathrm{C}$ in $5 \% \mathrm{CO}_{2}$. Afterwards cells were treated with different concentration of MPH and reaction was measured $24 \mathrm{~h}$ later. The assays were performed according to the manufacturer's protocol.

\section{Measurement and quantification of cell differentiation}

To determine neurite outgrowth, which is a hallmark of differentiated cells, of PC12 and SH-SY5Y cells the Neurite Outgrowth Kit purchased from Thermo Fisher Scientific (Switzerland) was used to stain the cell processes. The manufacturers protocol was slightly altered by substituting PBS with Opti-MEM (Thermo Fisher Scientific, Switzerland), since a loss of cells and breaking of longer neurites was observed when strictly adhering to the protocol. After aspiring the medium, the cells were stained with a working stain solution $(3 \mu \mathrm{l}$ of cell membrane indicator and $3 \mu \mathrm{l}$ cell viability indicator in $3 \mathrm{ml}$ Opti-MEM) for $15 \mathrm{~min}$. The stain solution was then replaced by a background suppressor solution and pictures were taken on the Olympus DP72 microscope, using $20 \times$ magnification. Per experiment, five representative images per condition containing at least five neurons were analyzed using the xcellence software (Olympus, Germany). To determine the differentiation state the ratio of neurite length to diameter of soma was taken as a reference. Astrocytes, glia cells and other cell types, which can still appear in cell culture, were not considered for analysis.

\section{Statistical analysis}

Statistical analysis was done using Prism (Graphpad Software, version 6.0). The statistical analysis of xCELLigence was done via StatView and MATLAB. Results are given as mean \pm s.e.m. Analysis was conducted using Mann-Whitney test with $p<0.05$ set as significant. For proliferation analysis over 18,000 cells were calculated and for differentiation study over 2100 cells. All experiments were repeated at least three times independently.

\section{Activity detection of canonical Wnt-signaling with luciferase Wnt reporter assay}

To confirm our pharmacological analysis of the Wntsignaling activation by $\mathrm{MPH}$ and R-Spondin1 against Wnt-signaling inhibition via Dkk1, we used the Leading Light Wnt Reporter Assay (Enzo Life Sciences, Lausen, Switzerland). The cell-based luciferase activity assay was conducted with some modifications to the manufacturer protocol (Supplementary Material And Methods). Following, Wnt agonist activity was run by adding to the cells either $5 \mu \mathrm{l} \mathrm{R}$-Spondin1 100-1000 ng/ml (Sigma, Switzerland), Wnt3a 5-200 ng/ml (abcam, Switzerland), $\mathrm{LiCl}$ 5-40 mM (Sigma, Switzerland), or MPH $1 \mathrm{nM}$ up to $1 \mathrm{mM}$ (all diluted in $\mathrm{H}_{2} \mathrm{O}$ ). Water was used as a negative control. Wnt antagonist activity test was conducted by adding to the cells already treated with Wnt3a $100 \mathrm{ng} / \mathrm{ml}$ the potential antagonist Dkk-1 20-200 ng/ml (5 $\mu$; Enzo Life Science, Switzerland), or $5 \mu \mathrm{l} \mathrm{MPH} 1 \mathrm{nM}$ up to $100 \mathrm{mM}$. Cells were incubated at least $12 \mathrm{~h}$, washed with PBS, followed by $15 \mathrm{~min}$ incubation with lysis buffer (Biotium, USA). Lysates were transferred into white microplate (Berthold, Germany) and mixed with luciferin assay buffer (Biotium, USA). Chemiluminescence reaction was measured immediately using the Mithras LB943 (Berthold, Germany) resulting in relative luciferase unite (RLU) measures. All experiments were conducted with 


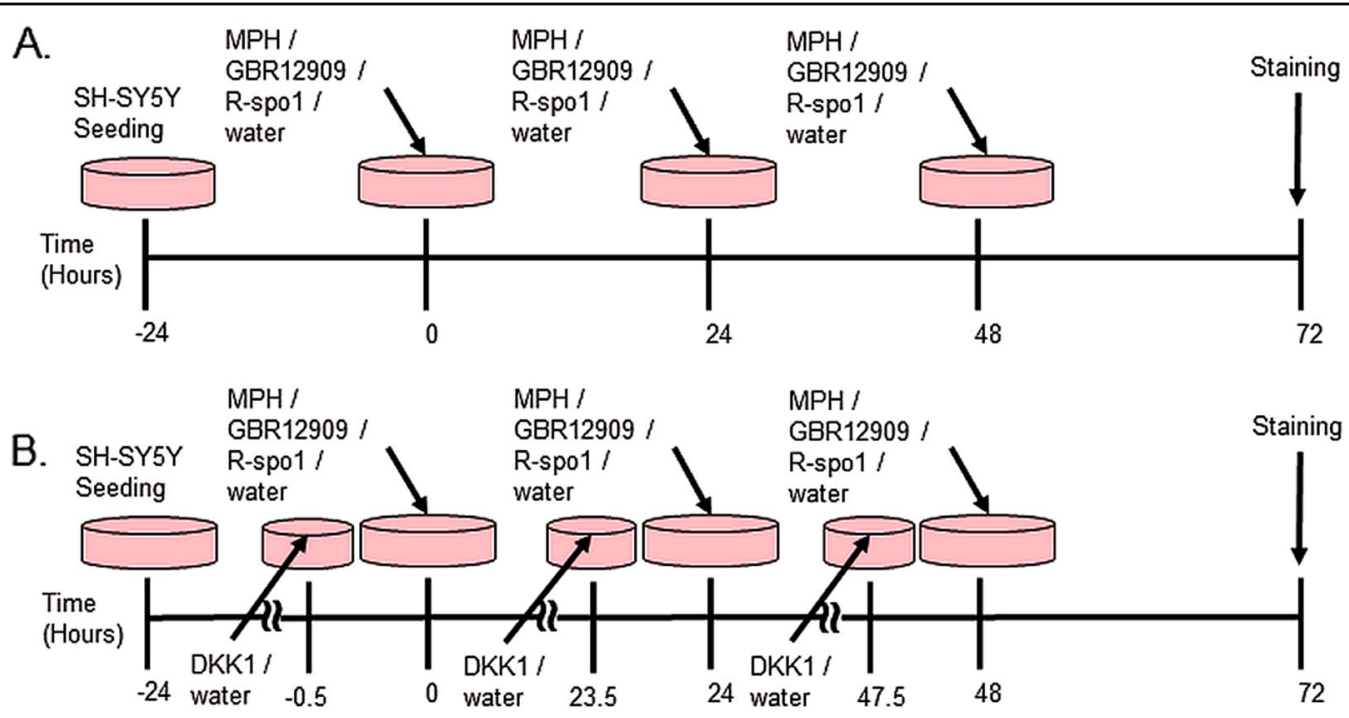

C.
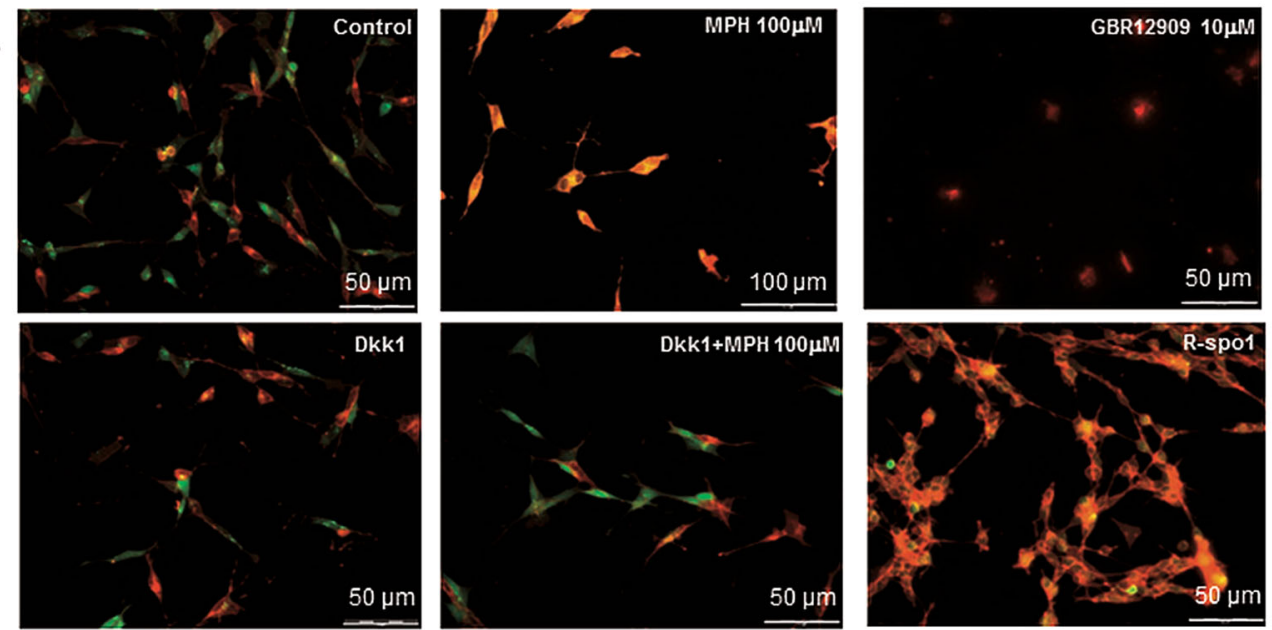

D.

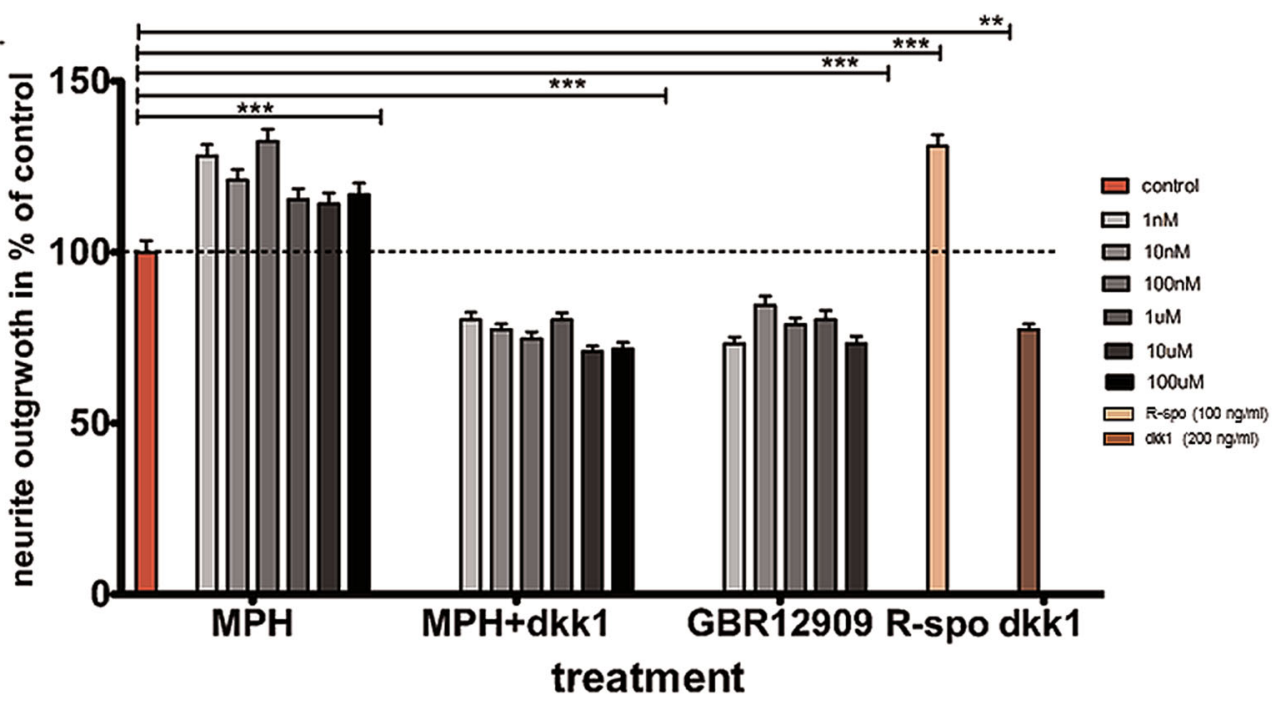

Fig. 4 (See legend on next page.) 


\begin{abstract}
(see figure on previous page)
Fig. 4 Influence of MPH treatment on SH-SY5Y cells differentiation and the involvement of Wnt-signaling. a The time line of cell culturing,

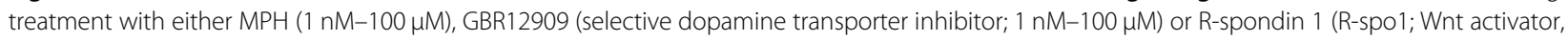
$100 \mathrm{ng} / \mathrm{ml}$ ) and neurite outgrowth determination via 'Neurite outgrowth staining kit' (Thermo Fisher) for differentiation evaluation. $\mathbf{b}$ The time line of cell culturing, inhibiting Wnt-signaling by treating cells with Dkk1 (LRP inhibitor; $200 \mathrm{ng} / \mathrm{ml}$ ) half an hour before MPH treatment and differentiation

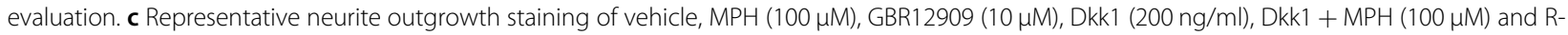
spondin $1(100 \mathrm{ng} / \mathrm{ml})$ treated SH-SY5Y cells. Scale bar $=50-100 \mu \mathrm{M}$. d Neurite outgrowth was significantly increased after MPH treatment, which was inhibited significantly by Dkk1 treatment. Similar to MPH, R-spondin 1 treatment increased significantly cell differentiation. However, the selective dopamine transporter inhibitor, GBR12909, caused a significant decrease in SH-SY5Y cell differentiation, while the higher dose of $100 \mu$ M induced cell death. $n=3-5$ independent experiment; $N=2172$ measured cells; Mann-Whitney test, ${ }^{* *} p<0.05,{ }^{* *} p<0.001$ vs. control
\end{abstract}

internal and external replications of 4-38. Regression was conducted using the exponential regression equation.

\section{Sclerostin-LRP interaction assay}

LRP might also be involved in MPH activation of Wntpathway, since activation of Wnt occurs via binding of Wnt-ligands to Frizzled $(\mathrm{Fz})$ and LRP receptor, triggering the canonical Wnt-signaling cascade ${ }^{25}$. In the regulation of bone formation, sclerostin, encoded by the SOST gene, can bind to LRP5/6, causing inhibition of the canonical Wnt signaling ${ }^{26}$. To evaluate, whether $\mathrm{MPH}$ interacts with the sclerostin-LRP binding, the Leading Light Sclerostin Interaction Screening (Enzo Life Sciences, Lausen, Switzerland) in a 96-well system was used, following manufacturer manual $\left(\mathrm{Z}^{\prime}\right.$-factor reproducibility $=$ 0.871). Fifty microliter $\mathrm{MPH}$ starting from $1 \mathrm{nM}$ up to $1 \mathrm{mM}$ all diluted in Assay Buffer (Enzo Life Sciences, Lausen, Switzerland) containing LRP-AP fusion protein, were added to the sclerostin pre-coated plate. As positive control for binding activation, only Assay buffer containing LRP-AP fusion protein was added. Each concentration was tested in 6-plicates. As negative control the sclerostin binding inhibitor Acid Green (Enzo Life Sciences, Lausen, Switzerland) and as background control Assay Buffer without LRP-AP was used. After incubation of two hours, wells were washed $4 \times$ followed by the addition of $50 \mu \mathrm{l}$ AP substrate reagent (Enzo) per well. After 25 min of incubation, chemiluminescence reaction was measured using the Mithras LB943 (Berthold, Germany) resulting in RLU measures. Statistical analysis was done using StatView (v. 5.0, SAS Institute Inc.). Results are given as mean RLU \pm s.e.m. Analysis was conducted using Kruskal-Wallis followed by Mann-Whitney test with $p<0.05$ set as significant.

\section{Gene expression omnibus (GEO) search for data sets of MPH treatment influence on transcriptomic profiling and enrichment analysis}

A search of data sets under GEO was conducted for gene expression profiling results after $\mathrm{MPH}$ treatment conducted in mammals with the keyword 'methylphenidate' and limiting the search to the 'expression profiling by array' study type. Three data sets could be found (excluding one dealing with autism spectrum disorder) using these terms: (1) MPH effect on mouse substantia nigra $^{27}$-GSE33619, (2) Psychostimulant (MPH, amphetamine and methamphetamine) effects on rat striatum and prefrontal cortex ${ }^{28}$-GSE33619, and (3) MPH effects on human lymphoblastoids ${ }^{29}$-GSE52889. Following this, each of the data sets were uploaded onto the Pathway Studio software (Elsevier; v. 11.4.08) to run the gene expression profiling and statistics correcting for multiple testing with Benjamin-Hochberg (FDR). The significant $(p<0.05)$ mRNA profiles found to alter as a consequence of MPH treatment were investigated for their enrichment in pathways and functional groups using the Gene-Set Enrichment Analysis (GSEA) tool of the Pathway Studio software (Elsevier; Mammal database), which calculates statistical significance of concordant differential expression for set of genes in pathways, groups, and predefined gene sets between two biological states using ratio (logratio) values of genes. Significant results $(p<0.0005)$ for enrichment analysis are presented in Supplementary Material S1. Gene Ontology (GO), pathways, diseases and signal processing related to brain or neuronal processes were marked in green, while Wnt-pathway was marked in blue (Supplementary Table S1).

\section{Data availability}

The data that support the findings of this study are available from the corresponding author upon request.

\section{Results}

\section{MPH effects on embryonic mNSC differentiation}

In order to expand on our previous pilot study ${ }^{20}$, we examined the acute effect of a range of $\mathrm{MPH}$ doses up to $100 \mu \mathrm{M}$ on embryonic mNSC differentiation. $\mathrm{MPH}$ treatment at $1 \mathrm{nM}$ and up to $100 \mathrm{nM}$ enhanced cell differentiation into immature neurons detected by positive staining for neuron-specific class III $\beta$-tubulin (Tuj1) (Fig. 1; Supplementary Fig. S1), similar to our previous pilot study $^{20}$. We expanded further on this finding and demonstrated that increasing MPH doses up to $100 \mu \mathrm{M}$ further increased immature neurons density to $207 \pm 39 \%$ 
of control (Mann-Whitney test $U=-2.021$, Asymp. $p=$ 0.043 , Exact $p=0.057$; Fig. 1). Additionally, mNSC treated with MPH in all doses did not result in a significantly different number of cells differentiating into astrocytes (Glial fibrillary acidic protein/ GFAP-positive staining) compared to control (Fig. 1). On the contrary, a tendency toward an inhibitory effect was observed when treating the cells with the lower dose of 1-100 nM MPH.

\section{Influence of MPH on rat PC12 cells proliferation and differentiation}

Following the possible influence of $\mathrm{MPH}$ on cell development, as found in the mNSC, we tested the effects of MPH on the proliferation of PC12 cells (Fig. 2). In order to evaluate cell proliferation in a non-invasive and non-biased manner, the real-time cell impedance automatic monitoring (xCELLigence system) was used for a duration of $72 \mathrm{~h}$ to evaluate the first significant time-point at which MPH caused alterations (Fig. 2b and Supplementary Fig. S2). Accordingly, 1-100 nM MPH significantly inhibited PC12 cell proliferation starting $16 \mathrm{~h}$ after treatment, which was further confirmed by assessing the 5-bromodeoxyuridine (BrdU) positive cells (Fig. 2c). In order to ensure that the effect did not arise from cell death, apoptosis and cytotoxicity were measured, and demonstrated negligible signals after MPH treatment (Supplementary Fig. S2d-e), suggesting that there was no significant cell death due to MPH.

Daily treatment (5 days) of MPH starting from a $10 \mathrm{nM}$ up to a $100 \mu \mathrm{M}$ dosage, significantly promoted PC12 cell differentiation, as observed by measuring neurite length normalized to the diameter of the soma (Fig. 2d-f).

\section{Influence of MPH on human SH-SY5Y cells proliferation and differentiation}

After testing proliferation and differentiation alterations following MPH treatment in two non-human cellular models (mouse and rat), we confirmed a decrease in the proliferation of SH-SY5Y cells after MPH treatment, as measured both by the real-time impedance cell analyzer and BrdU staining, starting with the lower $1 \mathrm{nM} \mathrm{MPH}$ dose (Fig. 3a, c, d). Furthermore, we confirmed that MPH significantly promoted the differentiation of SH-SY5Y cells (Fig. 4). To exclude the possibility that the effects of $\mathrm{MPH}$ on proliferation and differentiation were due to the dopamine transporter inhibition, SH-SY5Y cells were treated with the selective dopamine-transporter inhibitor GBR12909. GBR12909 (1 nM up to $10 \mu \mathrm{M})$ treatment did not cause a decrease in proliferation as with MPH (Fig. 3d), but rather a slight non-significant increase was observed. GBR12909 (1 nM up to $10 \mu \mathrm{M})$ treatment led to a significant decrease in differentiation (Fig. 4d), which was in contrast to MPH treatment effects. Furthermore, higher doses of GBR12909 (doses of $100 \mu \mathrm{M}$ ) caused cell death in both the proliferation and differentiation experiments, suggesting that increased extracellular dopamine might have caused cytotoxicity.

\section{Activation of Wnt/ $\beta$-catenin pathway through MPH treatment}

Examining whether the observed effects on proliferation and differentiation after MPH treatment were through the activation of the $\mathrm{Wnt} / \beta$-catenin pathway was investigated by blocking the Wnt-pathway with Dkk1 30 min before $\mathrm{MPH}$ treatment. Indeed, Dkk1 treatment caused a significant increase in the proliferation of SH-SY5Y cells (Fig. 3d), which remained constant after MPH treatment (30 min after blocking the pathway). Controlling for Wntactivation effects using R-spondin 1 treatment resulted in decreased proliferation as observed with MPH alone (Fig. 3d). Differentiation of SH-SY5Y cells was significantly inhibited by Dkk1 treatment $30 \mathrm{~min}$ before MPH treatment (Fig. 4d), whilst the activation of the Wnt-pathway with R-spondin 1 significantly increased differentiation similar to MPH treatment alone (Fig. 4d).

In order to verify the activation of Wnt-pathway through MPH treatment, the luciferase Wnt reporter assay was used, showing a dose response activation of the Wnt-pathway through Wnt3a, R-spondin 1 and $\mathrm{LiCl}$ (Supplementary Fig. S3a-c), while Dkk1 treatment led to an inhibition of the Wnt-pathway after Wnt3a treatment (Supplementary Fig. S3d). Similarly, MPH from $1 \mathrm{nM}$ up to $100 \mu \mathrm{M}$ resulted in an exponential increase in Wntsignaling activation (Fig. 5a). MPH treatment accompanied by $100 \mathrm{ng} / \mathrm{ml}$ Wnt3a protein enhanced the already occurring activation (Fig. 5b), in contrast to the inhibitory effect observed for Dkk1 when accompanied with $100 \mathrm{ng} /$ ml Wnt3a (Supplementary Fig. S3d).

LRP, in particularly 5 and 6 , is known to activate the canonical Wnt-signaling via binding with the Frizzle (Fz) and Wnt protein ${ }^{25}$. Several mechanisms are existing for regulating Wnt-signaling activation as the inhibitor Dkk1. Furthermore, sclerostin inhibits activation of Wntsignaling via binding to LRP5/6, which also regulates bone formation ${ }^{26}$. MPH inhibited LRP5 binding to sclerostin (ca, 17\%) measured using the Leading Light Sclerostin-LRP interaction screening kit (Enzo Life Sciences Inc. Lausen, Switzerland) in all doses tested (1 nM up to $1 \mathrm{mM}$ ) with the strongest inhibition at $1 \mathrm{mM} \mathrm{MPH}$ (Supplementary Fig. S4).

\section{Enrichment analysis for GEO profiles following MPH treatment}

We re-analyzed three available gene expression profile data sets extracted from the GEO database, from experiments studying $\mathrm{MPH}$ treatment effects in mouse substantia nigra ${ }^{27}$, in rat striatum and frontal cortex ${ }^{28}$, and in immortalized human lymphocytes of controls and adult 

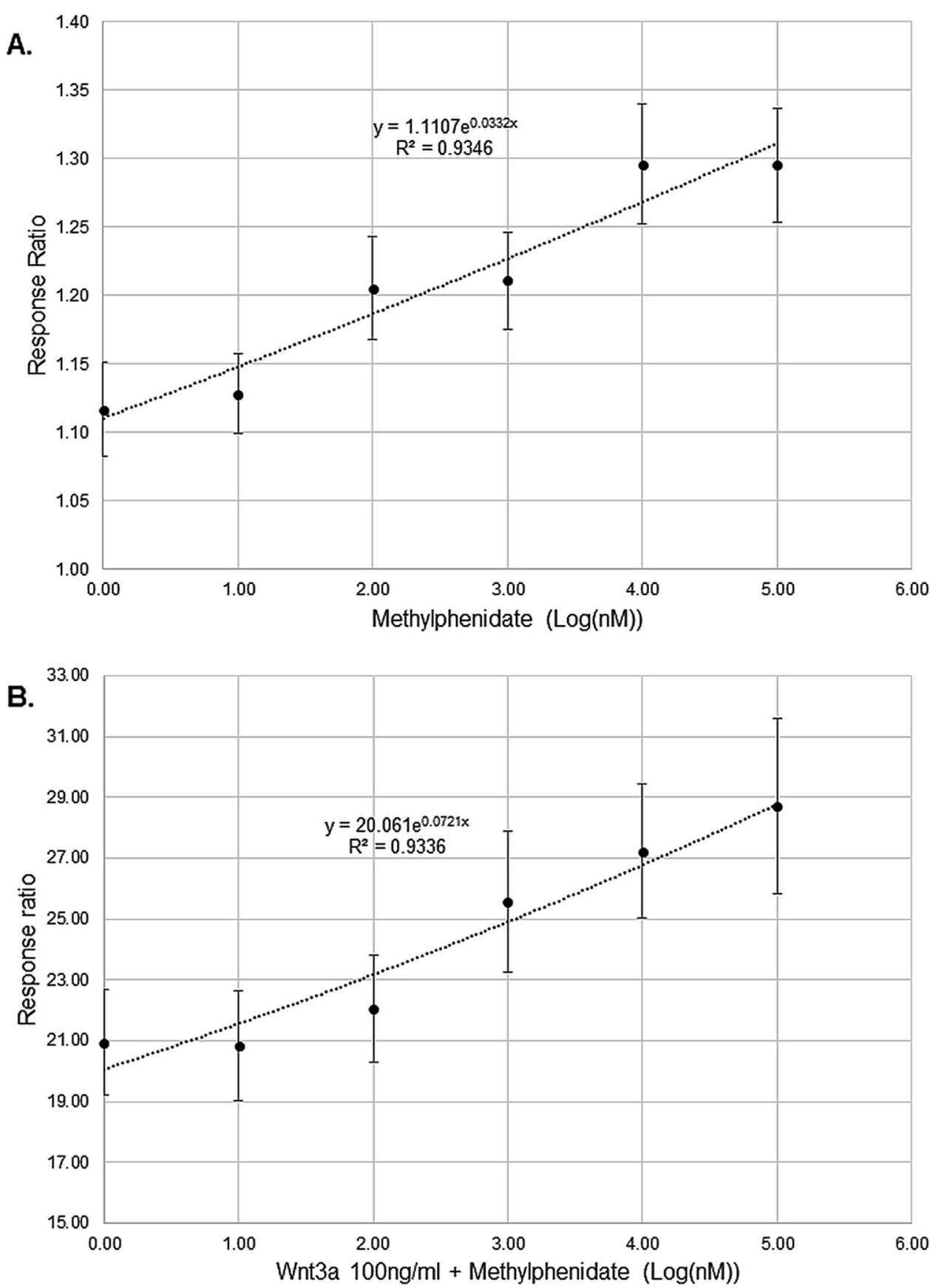

Fig. 5 Effect of MPH on the luciferase Wnt reporter assay activation/inhibition. a Dose response of MPH on the activation of the leading light Wht reporter assay represented as response ration (ratio $=1$ negative control-water); $\mathbf{b}$ Dose response of $\mathrm{MPH}$ in the presence of Wnt3a $(100 \mathrm{ng} / \mathrm{ml})$ on the activation/inhibition of the Leading Light Wnt reporter assay represented as response ration (ratio = 1 negative control-water); $n=17-35$; Exponential regression was conducted fitting the curve with $R^{2}>0.9$

ADHD patients ${ }^{29}$, in which in the last study cell lines were acutely treated with ca. $111 \mu \mathrm{M}$ MPH. Pathway enrichment analysis for all significantly altered transcripts was carried out using the GSEA. Indeed, we found some indication that in vivo MPH treatment in mice and rats induced mRNA alterations enriched in pathways involved in cell differentiation and Wnt-signaling, as well as in synaptic, axonal and neuronal processes (Supplementary material S1). The top ranked pathways were of general processes, such as plasma membrane, atlas signaling, cell differentiation, signal transduction etc. followed by the aforementioned pathways with $p$-values lower than 
0.0005. In the human lymphoblastoids, enrichment in synaptic, axonal and neuronal processes was observed when comparing between adult ADHD and control cells treated with saline, and in negative regulation of cell proliferation and axonal guidance in cells treated with ca. $111 \mu \mathrm{M}$ MPH (Supplementary material S1).

\section{Discussion}

This study found that MPH influences proliferation and differentiation processes through Wnt-signaling activation. Evidence for Wnt-signaling activation through $\mathrm{MPH}$ treatment was demonstrated using the cell culture model, the luciferase Wnt-reporter assay as well as from GSEA results of three gene expression databases in animals and humans following $\mathrm{MPH}$ treatment. In all the above experiments, we repeatedly confirmed that MPH treatment led to an alteration in Wnt-signaling pathways, which at the cellular level promoted cell differentiation concomitantly to reduced proliferation.

Modulation of Wnt-signaling components is known to be induced by cocaine, an addictive psychostimulant. Cocaine has been shown to cause a widespread downregulation of Wnt-signaling molecules in the nucleus accumbens of mice, a key brain region in reward ${ }^{30}$, as well as a downregulation of the Wnt-canonical pathway after induction of cocaine sensitization in the prefrontal cortex of rats, amygdala and dorsal striatum ${ }^{31}$. On the other hand, amphetamine, (another first-line treatment of ADHD, e.g., according to the often used Canadian guidelines (CADDRA) and second-line treatment according to the most other guidelines), reportedly stimulated Wnt3 with an increase in total $\beta$-catenin in rat nucleus accumbens ${ }^{32}$. In adult mice with inducible expression of Dkk1, there was a degeneration of corticostriatal synapses, but amphetamine did not increase locomotion as compared to those treated with saline ${ }^{33}$. However, induced Dkk1 adult mice were already slightly hyperactive compared with control animals ${ }^{33}$, which suggest that developmental timing of such induced imbalance is important in Wnt activity. Although one might hypothesize that psychostimulants effects on Wntsignaling may be due to monoamine levels or dopamine receptor activity modulation, we did not observe such changes after treatment with the selective dopaminetransporter inhibitor GBR12909. Moreover, an increased dose of GBR12909 led to cell death that was not observed with $\mathrm{MPH}$, even after higher doses. Although this suggests that MPH has a direct interaction with Wnt-pathways, this requires further investigation.

Alterations during neurogenesis and the plasticity of the developing brain, as well as later in life, are often discussed to be vulnerability factors for the development of psychiatric disorders, such as ADHD. Wnt-signaling has been shown to regulate both embryonal neurogenesis, in particular in the dopaminergic system ${ }^{22}$, as well as adult neurogenesis processes mostly known to occur in the hippocampus ${ }^{23}$. Various animal models and paradigms have demonstrated MPHs capability to modulate neurogenesis and brain plasticity ${ }^{15-17,34}$. Recently, personalized fingerprinting of brain functional connectome demonstrated sensitive time points in brain maturation and plasticity, that were distinctively different to those with symptoms such as attention deficit ${ }^{35,36}$. Psychostimulant treatment in ADHD was reported to induce changes in functional brain connectivity, which were also associated with symptom improvements ${ }^{37,38}$. Such alterations need to be further understood in terms of the optimum time point and duration of treatment with psychostimulants to reach best results and benefits.

There is some evidence for candidate risk genes in ADHD to be enriched in pathways such as neurite outgrowth, axon guidance, cell trafficking processes, brain development, neurogenesis, and $\mathrm{Wnt} / \beta$-catenin pathway $^{39-41}$. Wnt-signaling is known to play an important role in the development and survival of neuronal cells in the CNS. Moreover, growing evidence indicates that Wntsignaling pathways also regulate the structure and function of the adult nervous system. Wnt-signaling was shown to regulate the formation and function of neuronal circuits by controlling neuronal differentiation, axon outgrowth and guidance, dendrite development, synaptic function, and neuronal plasticity ${ }^{42,43}$. Genome-wide association studies (GWAS) have reported the KCNIP4 gene, known to be associated with ADHD, plays a role in a negative-feedback loop in the Wnt/ $\beta$-catenin pathway ${ }^{44}$. Several GWAS and candidate gene studies describe the association of $\mathrm{CDH} 13$ (encodes the cadherin-13 protein) and CTNNA2 (encodes the $\alpha 2$-catenin protein) genes with ADHD or with associated phenotypes (e.g., hyperactivity/impulsivity symptoms; verbal working-memory ${ }^{45-47}$ pointing to alterations in the Wnt-associated genes in ADHD. Furthermore, an enrichment analysis of a GWAS analyzing the association in a subpopulation of oppositional defiant disorder in ADHD found the $\beta$ catenin to be significantly highlighted ${ }^{48}$. In the often comorbid disorder, autism spectrum disorder (ASD), evidence from human genetic data to animal genetic models also point to the involvement of Wnt-pathway (see review in ref. 49). In summary, this evidence of dysregulation of Wnt-pathways in ADHD might also predict the efficacy of $\mathrm{MPH}$ treatment in some patients compared to nonresponders. However, this needs further investigation using patient specific cellular models, i.e., induced pluripotent stem cells (iPSC).

In conclusion, this study has shed some light on to the additional targets of MPH and its influence on cell proliferation and differentiation. Wnt-signaling alterations through MPH points to the importance of gaining further 
understanding of its short-term and long-term effects and duration of treatment. Studies using patients' specific neuronal models will greatly improve the accessibility of human tissue, which is currently limited due to scarce postmortem samples from ADHD patients.

\section{Acknowledgements}

We credit the excellent technical assistance of Miryame Hofmann, Susanne Kunert-Dümpelmann and Seema Mehta. Furthermore, we wish to credit the students Katharina Schmidt, Terry Louise Jones, Stefania Niedecker and Joële Saxer. We acknowledge the support of the UZH Forschungskredit.

\section{Author details}

'Department of Child and Adolescent Psychiatry and Psychotherapy, University Hospital of Psychiatry Zurich, University of Zurich, Zürich, Switzerland.

${ }^{2}$ Neuroscience Center Zurich, University of Zurich and the ETH Zurich, Zürich, Switzerland. ${ }^{3}$ Zurich Center for Integrative Human Physiology, University of Zurich, Zürich, Switzerland. ${ }^{4}$ Department of Pediatric Oncology, Hematology, and Clinical Immunology, University Hospital Düsseldorf, Düsseldorf, Germany

\section{Author Contributions}

E.G., J.B., and S.W. conceived, designed, and directed the project. J.B. and E.G. conducted the experiments. E.G. and J.B. conduced the data analyses. E.G. and J.B. wrote and SW reviewed the paper.

\section{Conflict of interest}

S.W. has received lecture honoraria from Eli-Lilly and Opopharma in the last 5 years. Her work was supported in the last 5 years by the Swiss National Science Foundation (SNF), various EU FP7s, Hochspezialisierte Medizin (HSM) of the Kanton Zurich, Switzerland, Bfarm Germany, ZInEP, Hartmann Müller Stiftung and Olga Mayenfisch. Outside professional activities and interests are as follows: President of Association of Chief Physicians of the Swiss Society for Child and Adolescent Psychiatry and Psychotherapy (VKJC), board member of Swiss Society for Child and Adolescent Psychiatry and Psychotherapy (SGKJPP); co-director of the board of the institute for psychotherapy of child and adolescent of the university clinics Basel-Bern-Zurich; member of the academy for behavioral therapy in child and adolescents (AVKJ); member of the board of Swiss society for anxiety and depressive disorders (SGAD); vice president of the Swiss society for obsessive compulsive disorders (SGZ); and declare no biomedical financial interests. The authors, E Grünblatt and J. Bartl declare no biomedical financial interests or potential conflict of interest. The study was funded by the University of Zurich ( $\mathrm{UZH})$ and the postdoc of J. Bartl by the UZH Forschungskredit.

\section{Publisher's note}

Springer Nature remains neutral with regard to jurisdictional claims in published maps and institutional affiliations.

Supplementary Information is available for this paper at https://doi.org/ 10.1038/s41398-018-0096-8.

Received: 17 October 2017 Revised: 5 December 2017 Accepted: 30 December 2017

Published online: 01 March 2018

\section{References}

1. Thomas, R., Sanders, S., Doust, J., Beller, E. \& Glasziou, P. Prevalence of attentiondeficit/hyperactivity disorder: a systematic review and meta-analysis. Pediatrics 135, e994-e100 (2015).

2. Shaw, P. et al. Development of cortical surface area and gyrification in attention-deficit/hyperactivity disorder. Biol. Psychiatry 72, 191-197 (2012).

3. Silk, T. J. et al. Cortical morphometry in attention deficit/hyperactivity disorder: contribution of thickness and surface area to volume. Cortex 82, 1-10 (2016).

4. Shaw, P. et al. Trajectories of cerebral cortical development in childhood and adolescence and adult attention-deficit/hyperactivity disorder. Biol. Psychiatry 74, 599-606 (2013).
5. Shaw, P. et al. Mapping the development of the basal ganglia in children with attention-deficit/hyperactivity disorder. J. Am. Acad. Child Adolesc. Psychiatry 53, 780-789 (2014). e711.

6. Paclt, I. et al. Reverse asymmetry and changes in brain structural volume of the basal ganglia in ADHD, developmental changes and the impact of stimulant medications. Neuro Endocrinol. Lett. 37, 29-32 (2016).

7. Faraone, S. V. \& Buitelaar, J. Comparing the efficacy of stimulants for ADHD in children and adolescents using meta-analysis. Eur. Child Adolesc. Psychiatry 19, 353-364 (2010).

8. Gerlach, M., Grünblatt, E. \& Lange, K. W. Is the treatment with psychostimulants in children and adolescents with attention deficit hyperactivity disorder harmful for the dopaminergic system? Atten. Defic. Hyperact Disord. 5, 71-81 (2013).

9. Rubia, K. et al. Effects of stimulants on brain function in attention-deficit/ hyperactivity disorder: a systematic review and meta-analysis. Biol. Psychiatry 76, 616-628 (2014).

10. Villemonteix, T. et al. Grey matter volumes in treatment naive vs. chronically treated children with attention deficit/hyperactivity disorder: a combined approach. Eur. Neuropsychopharmacol. 25, 1118-1127 (2015).

11. Shaw, P. et al. Psychostimulant treatment and the developing cortex in attention deficit hyperactivity disorder. Am. J. Psychiatry 166, 58-63 (2009).

12. Han, D. D. \& Gu, H. H. Comparison of the monoamine transporters from human and mouse in their sensitivities to psychostimulant drugs. BMC Pharmacol. 6, 6 (2006).

13. Bogle, K. E. \& Smith, B. H. Illicit methylphenidate use: a review of prevalence, availability, pharmacology, and consequences. Curr. Drug Abus. Rev. 2, 157-176 (2009).

14. Benson, K., Flory, K., Humphreys, K. L. \& Lee, S. S. Misuse of stimulant medication among college students: a comprehensive review and meta-analysis. Clin. Child Fam. Psychol. Rev. 18, 50-76 (2015).

15. Lee, T. H. et al. Effects of ADHD therapeutic agents, methylphenidate and atomoxetine, on hippocampal neurogenesis in the adolescent mouse dentate gyrus. Neurosci. Lett. 524, 84-88 (2012).

16. Schaefers, A. T., Teuchert-Noodt, G., Bagorda, F. \& Brummelte, S. Effect of postnatal methamphetamine trauma and adolescent methylphenidate treatment on adult hippocampal neurogenesis in gerbils. Eur. J. Pharmacol. 616, 86-90 (2009).

17. van der Marel, K. et al. Effects of long-term methylphenidate treatment in adolescent and adult rats on hippocampal shape, functional connectivity and adult neurogenesis. Neuroscience 309, 243-258 (2015).

18. Studer S. et al. Methylphenidate and ritalinic acid determination in serum and saliva from patients with attention deficit hyperactivity disorder. Pharmacopsychiatry 47-A4 (2014). https://doi.org/10.1055/s-0034-1386830

19. Gualtieri, C. T. et al. Clinical studies of methylphenidate serum levels in children and adults. J. Am. Acad. Child Psychiatry 21, 19-26 (1982).

20. Bartl, J., Mori, T., Riederer, P., Ozawa, H. \& Grünblatt, E. Methylphenidate enhances neural stem cell differentiation. J. Mol. Psychiatry 1, 5 (2013).

21. Urban, N. \& Guillemot, F. Neurogenesis in the embryonic and adult brain: same regulators, different roles. Front Cell Neurosci. 8, 396 (2014).

22. Luo, S. X. \& Huang, E. J. Dopaminergic neurons and brain reward pathways: from neurogenesis to circuit assembly. Am. J. Pathol. 186, 478-488 (2016).

23. Lie, D. C. et al. Wnt signalling regulates adult hippocampal neurogenesis. Nature 437, 1370-1375 (2005).

24. Bengoa-Vergniory, N. \& Kypta, R. M. Canonical and noncanonical Wnt signaling in neural stem/progenitor cells. Cell Mol. Life Sci. 72, 4157-4172 (2015).

25. MacDonald, B. T., Tamai, K. \& He, X. Wnt/beta-catenin signaling: components, mechanisms, and diseases. Dev. Cell 17, 9-26 (2009).

26. Duan, P. \& Bonewald, L. F. The role of the wnt/beta-catenin signaling pathway in formation and maintenance of bone and teeth. Int J. Biochem Cell Biol. 77(Pt A), 23-29 (2016).

27. Sadasivan, S. et al. Methylphenidate exposure induces dopamine neuron loss and activation of microglia in the basal ganglia of mice. PLoS One 7, e33693 (2012).

28. Dela Pena, I. et al. Neuronal development genes are key elements mediating the reinforcing effects of methamphetamine, amphetamine, and methylphenidate. Psychopharmacol. (Berl.) 230, 399-413 (2013).

29. Schwarz, R. et al. A preliminary study on methylphenidate-regulated gene expression in lymphoblastoid cells of ADHD patients. World J. Biol. Psychiatry 16, 180-189 (2015).

30. Dias, C. et al. Dishevelled-2 regulates cocaine-induced structural plasticity and Rac1 activity in the nucleus accumbens. Neurosci. Lett. 598, 23-28 (2015). 
31. Cuesta, S., Severin, M. J., Batuecas, J., Rosso, S. B. \& Pacchioni, A. M. Wnt/betacatenin pathway in the prefrontal cortex is required for cocaine-induced neuroadaptations. Addict. Biol. 22, 933-945 (2017).

32. MacLeod, R. J., Moores, M. E. \& Beninger, R. J. Amphetamine stimulates Wnt3 increases in rat nucleus accumbens. Neuroreport 23, 846-850 (2012).

33. Galli, S. et al. Deficient Wnt signalling triggers striatal synaptic degeneration and impaired motor behaviour in adult mice. Nat. Commun. 5, 4992 (2014).

34. Jenson, D. et al. Dopamine and norepinephrine receptors participate in methylphenidate enhancement of in vivo hippocampal synaptic plasticity. Neuropharmacology 90, 23-32 (2015).

35. Galvan, A. Adolescence, brain maturation and mental health. Nat. Neurosci. 20 503-504 (2017).

36. Kaufmann, T. et al. Delayed stabilization and individualization in connectome development are related to psychiatric disorders. Nat. Neurosci. 20, 513-515 (2017).

37. Schweren, L. J. et al. Stimulant treatment history predicts frontal-striatal structural connectivity in adolescents with attention-deficit/hyperactivity disorder. Eur. Neuropsychopharmacol. 26, 674-683 (2016).

38. Silberstein, R. B., Levy, F., Pipingas, A. \& Farrow, M. First-dose methylphenidateinduced changes in brain functional connectivity are correlated with 3-month attention-deficit/hyperactivity disorder symptom response. Biol. Psychiatry $\mathbf{8 2}$, 679-686 (2017).

39. Mooney, M. A. et al. Pathway analysis in attention deficit hyperactivity disorder: an ensemble approach. Am. J. Med Genet B Neuropsychiatr. Genet 171, 815-826 (2016).

40. Poelmans, G., Pauls, D. L., Buitelaar, J. K. \& Franke, B. Integrated genomewide association study findings: identification of a neurodevelopmental network for attention deficit hyperactivity disorder. Am. J. Psychiatry 168, 365-377 (2011).

41. Nakka, P., Raphael, B. J. \& Ramachandran, S. Gene and network analysis of common variants reveals novel associations in multiple complex diseases. Genetics 204, 783-798 (2016).

42. Schubert, D., Martens, G. J. \& Kolk, S. M. Molecular underpinnings of prefrontal cortex development in rodents provide insights into the etiology of neurodevelopmental disorders. Mol. Psychiatry 20, 795-809 (2015).

43. Rosso, S. B. \& Inestrosa, N. C. WNT signaling in neuronal maturation and synaptogenesis. Front Cell Neurosci. 7, 103 (2013)

44. Weissflog, L. et al. KCNIP4 as a candidate gene for personality disorders and adult ADHD. Eur. Neuropsychopharmacol. 23, 436-447 (2013).

45. Neale, B. M. et al. Case-control genome-wide association study of attentiondeficit/hyperactivity disorder. J. Am. Acad. Child Adolesc. Psychiatry 49, 906-920 (2010).

46. Lesch, K. P. et al. Molecular genetics of adult ADHD: converging evidence from genome-wide association and extended pedigree linkage studies. J. Neural Transm. Vienna) 115, 1573-1585 (2008).

47. Salatino-Oliveira, A. et al. Cadherin-13 gene is associated with hyperactive/ impulsive symptoms in attention/deficit hyperactivity disorder. Am. J. Med. Genet. B Neuropsychiatr. Genet. 168B, 162-169 (2015).

48. Aebi, M. et al. Gene-set and multivariate genome-wide association analysis of oppositional defiant behavior subtypes in attention-deficit/ hyperactivity disorder. Am. J. Med. Genet. B Neuropsychiatr. Genet. 171, 573-588 (2016).

49. Kwan, V., Unda, B. K. \& Singh, K. K. Wnt signaling networks in autism spectrum disorder and intellectual disability. J. Neurodev. Disord. 8, 45 (2016). 